\title{
SUCCESSFUL REPAIR OF A RUPTURED ANEURYSM OF THE AORTIC SINUS
}

\author{
BY \\ K. BLOOR, W. K. DOUG LAS, AND A. G. RIDDELL \\ From the University Department of Surgery, Manchester Royal Infirmary
}

(RECEIVED FOR PUBLICATION AUGUST 21, 1961)

Congenital aneurysm of the aortic sinus, with or without rupture, is a rare occurrence. Sawyers, Adams, and Scott (1957) found only 47 cases in the literature, of which 37 had ruptured. Since surgical repair has become possible, interest has quickened and a further 35 cases have since been described (Johnson, 1957 ; Cooley, 1957 ; Bosher, 1957; Lillehei, Stanley, and Varco, 1957; Husfeldt and Davidsen, 1957 ; Morrow, Baker, Hanson, and Mattingly, 1957 ; Brofman and Elder, 1957 ; Weiss, 1957 ; McGoon, Edwards, and Kirklin, 1958 ; Steinberg and Sammons, 1958 ; Bigelow and Barnes, 1959; Mouquin, Dubost, Maurice, and Hatt, 1958; Buzzi, 1959; Jick, Karsarjian, and Barsky, 1959; Winfield, 1959; Hall and Pickard, 1959; Lippschutz and Wood, 1960 ; Kieffer and Winchell, 1960 ; Spencer, Blake, and Bahnson, 1960; Gibbs and Harris, 1961).

\section{Aetiology and Anatomy}

Congenital aneurysms are due to a deficiency in the aortic wall between the ascending aorta and the annulus fibrosus of the aortic valve (Edwards and Burchell, 1956). More rarely aneurysms at this site are due to syphilis or mycotic infections. The certain differentiation of mycotic from congenital aneurysm may be impossible even at necropsy, since bacterial endocarditis affecting the aortic valve may occur and produce a mycotic aneurysm of the aortic sinus, or a bicuspid aortic valve associated with a congenital aneurysm of the aortic sinus may be affected by a bacterial infection (Hall and Pickard, 1959). The pathological end-result of both these processes will be the same.

Congenital aneurysms are finger-like projections formed presumably after birth, when the weak aortic wall gives way under the aortic pressure. Extension into any adjacent structure may occur. The subject has been reviewed by Jones and Langley (1949), by Oram and East (1955), by Sawyers et al. (1957), and by Kieffer and Winchell
(1960). Aneurysms are seen most frequently in the right coronary sinus, less often in the noncoronary sinus, and rarely in the left coronary sinus.

A right coronary sinus aneurysm usually ruptures into the right ventricle or less commonly into the right atrium. Rupture may also occur into the pericardium (Weiss, 1957), the pulmonary artery, or into both the right atrium and ventricle simultaneously (Oram and East, 1955). The aneurysm may burrow through the interventricular septum rupturing into the left ventricle (Warthen, 1949) ; it could presumably be found rupturing into both ventricles, since the aneurysm described by Raman and Menon (1949), although unruptured, presented in both these chambers. The base of the aneurysm is usually small but may be as large as $2 \mathrm{~cm}$. in diameter; in the aneurysm described by Weiss (1957) there were two holes in its base through the aortic wall.

Non-coronary sinus aneurysms usually rupture into the right atrium, but one has been described rupturing into the right ventricle (Kieffer and Winchell, 1960).

Intracardiac rupture from a left coronary sinus aneurysm has been seen (Spencer et al., 1960). The aneurysm burrowed into the interatrial septum, presenting in both chambers and bursting into the right atrium.

Acute and subacute bacterial endocarditis may occur in the aneurysmal sac and precipitate rupture through several small holes (Jick et al., 1959 ; Bigelow and Barnes, 1959). Other lesions may coexist with a sinus aneurysm such as bicuspid aortic valves, ventricular septal defects, and the tetralogy of Fallot (Lillehei et al., 1957). In addition, unruptured aneurysms have been seen in association with coarctation of the aorta (Steinberg and Sammons, 1958). Ventricular septal defects have been found with aneurysms of the right coronary sinus which projected into the right ventricle: they are sited immediately below the aneurysm, separated from it by the aortic 
valve ring (McGoon et al., 1958; Brofman and Elder, 1957). Aneurysms may also interfere with the conduction bundle and with a coronary artery sufficiently to cause myocardial infarction (Kieffer and Winchell, 1960).

Rupture can happen at any age. Weiss (1957) reported a patient who was 72 years. Death may result immediately, but survival up to 15 years has been reported. The average length of survival after rupture is 3.2 years, but this includes one or two very long surviving patients (Sawyers et al., 1957).

\section{Diagnosis of Ruptured ANEurysm}

The patient is usually well up to the time of rupture, although a cardiac murmur may have been noted previously due either to a coexisting lesion or to a small hole in the aneurysm (Lillehei et al., 1957). Rupture is usually, but not necessarily, a dramatic event causing breathlessness and epigastric and chest pain, made worse by exercise. Evidence of cardiac failure may develop rapidly. A loud machinery murmur similar to that associated with patency of the ductus arteriosus is heard at either side of the sternum opposite the second and third intercostal spaces, accompanied by a thrill. The pulse pressure is wide and the diastolic low or unobtainable. A diagnosis is usually possible on history and findings, without ancillary investigations.

Cardiac catheterization will show an increased atrial or ventricular pressure and increased oxygenation in the right chambers. The catheterization findings could be mimicked in abnormal connexions between the coronary arteries and the right chambers of the heart. Catheterization will also differentiate an uncomplicated aortic sinus aneurysm from patent ductus or aorto-pulmonary septal defects.

Aortography may show the site of rupture if the leak is not too great (Husfeldt and Davidsen, 1957). Injection of dye into the ascending aorta with sampling from various chambers of the heart will also localize the leak and differentiate from aortic valve regurgitation in combination with a ventricular septal defect (Semler and Brandenburg, 1958).

In the case to be reported none of these investigations was carried out, as the patient was considered too ill; exploration was undertaken on clinical grounds alone.

\section{CASE RePort}

The patient, a 35-year-old man, was admitted to the Department of Cardiology at the Manchester Royal Infirmary on September 22, 1960. At the age of 5 years he had been in an isolation hospital when a cardiac lesion was diagnosed, and until the age of 10 years he was made to restrict his activities. Subsequently he played football and cricket without difficulty. In June, 1960, he suddenly developed pain in the throat and epigastrium on walking 100 yards, with relief after a half-minute halt. This became progressively worse, and he was seen at Stockport Infirmary by Dr. R. M. Fulton, who made a diagnosis of ruptured aortic sinus aneurysm and transferred him to the Manchester Royal Infirmary. $\mathrm{He}$ was distressed and cyanosed and showed early finger clubbing. The blood pressure was $165 / 45$. The heart was enlarged, and there was an easily palpable thrill and loud continuous murmur over the whole praecordium, maximal in the left second, third, and fourth intercostal spaces by the sternum. The liver was enlarged one finger's breadth below the costal margin and the venous pressure was raised. The electrocardiogram showed non-specific S-T change and numerous ventricular extrasystoles. A radiograph of the chest showed cardiac enlargement which appeared to be mainly in the left ventricle. The gravity of his illness precluded catheterization. Cyanosis and peripheral oedema increased rapidly despite treatment, and operation was decided upon without further delay.

\section{OPERATION}

This was undertaken on October 5,1960 , by total cardiac bypass using a Melrose N.E.P. heart-lung machine with cooling to an oesophageal temperature of $28^{\circ} \mathrm{C}$. The heart was enormous and only the right ventricle and a small part of the right atrium were visible on exposure through a median sternotomy incision. The pulmonary artery was also grossly dilated. A thrill could be felt, maximal in a small area about $3 \mathrm{~cm}$. below the origin of the pulmonary artery. After placement of the venous and arterial cannulae, perfusion was commenced without difficulty and a satisfactory arterial pressure was maintained despite the leak from the aorta. Perfusion was continued with cooling for 10 minutes until the oesophageal temperature reached $29^{\circ}$ C., before the aorta was cross-clamped: a right ventriculotomy was performed. A small tag of tissue was found at the base of the aorta which, when extended, was a tube $1 \mathrm{~cm}$. long and about $4 \mathrm{~mm}$. wide at its base, with two oblique holes in the distal end each about $3 \mathrm{~mm}$. wide. The base was surrounded by aortic wall of normal appearance and thickness. The base of the aneurysm was oversewn with 000 silk and the aortic clamp relaxed. This revealed a leak in the suture line and a further layer of sutures was added, preventing further leakage. Two minutes after the application of the aortic clamp, ventricular fibrillation had occurred. This supplied 
the equivalent of a still heart. After closure of the ventriculotomy incision the coronary blood flow distended the right atrium because of the functional inactivity of the heart. This difficulty was overcome by loosening the caval slings when the coronary flow returned to the pump via the venous cannulae. Rewarming commenced as soon as the aneurysm was satisfactorily oversewn, and when the oesophageal temperature was $32.5^{\circ}$ C. defibrillation was obtained by a single shock at 150 volts. The total duration of perfusion was 60 minutes which included a period of partial bypass for the purpose of rewarming. The patient's immediate post-operative recovery was uneventful, but on the fifth day he had a pulmonary embolus which was treated by anticoagulants, continued for six weeks postoperatively. A diuresis commenced immediately post-operatively, even before the administration of diuretics, the cyanosis disappeared, and the immediate change in his appearance due to these two factors was very striking.

A faint systolic and diastolic murmur could be heard after operation in the area of maximal intensity of his previous machinery murmur. This diminished and on April 18, 1961, the diastolic component could not be heard.

Immediately after repair his blood pressure became $130 / 80$ and has remained at this level. A radiograph of the chest on April 18, 1961, showed considerable diminution of the cardiac shadow which was then within normal limits.

\section{Discussion}

A patient with a history of a cardiac murmur prior to rupture may well have an associated lesion such as a bicuspid aortic valve. Alternatively, he may, like the patient described by Lillehei et al. (1957), have had a small hole in the aneurysm of no functional significance. In our patient the cause of the cardiac murmur heard in childhood is not known. If the residual murmur persists, it might well be due to an associated lesion, but this presumably would be of little significance in view of his previous good health. If the residual murmur disappears, it may be presumed that he had had a small hole in the aneurysm since childhood.

The diagnosis of ruptured aortic sinus aneurysm can be made confidently in the patient with typical history and physical signs, but even if all ancillary investigations are carried out the exact anatomy may remain uncertain. When the possible variations of origin and site of rupture are considered, it is obvious that thorough exploration of the heart is essential and that operation must be undertaken by a method which gives ample time for exploration, repair, and confirmation of the success of repair.

To recapitulate, some of these variations of immediate interest to the surgeon are as follows. First, rupture may occur into two chambers. In the attempted closure reported by Oram and East (1955) the aneurysm had ruptured into both the right atrium and the right ventricle. This was not realized at the time and only the atrial part was sutured: the patient subsequently died. Presumably the best way to repair such an aneurysm would be to patch it from inside the aorta, suturing the tricuspid annulus to the patch. The possibility of double rupture into both atria or both ventricles must be remembered.

Aneurysms with large bases will require a Teflon patch; rupture into the right ventricle with an associated ventricular septal defect is conveniently treated by a single patch placed over both defects, suturing the aortic annulus to the middle of the patch in addition (McGoon et al., 1958 ; Brofman and Elder, 1957).

If an opening into the right atrium is found with no obvious communication with the aorta, it is possibly arising in the left coronary sinus via a tortuous track through the atrial septum. To be certain of this it is necessary to open the aorta, from which aspect the defect may be repaired with less likelihood of injury to the left coronary artery (Spencer et al., 1960).

Several attempts at repair were made with both hypothermia and total cardiac bypass before success was achieved (Table I). These unsuccessful attempts were reported by Oram and East (1955), by Husfeldt and Davidsen (1957), by Sawyers et al. (1957), by Brofman and Elder (1957), and in the discussion following the paper by Sawyers et al. (1957). In this discussion Cooley (1957) reported a success using cardiac bypass. A total of 14 survivals following operation have been reported, making the present authors' case the fifteenth, but two of these have apparently unsatisfactory results. No recurrence after satisfactory repair has been reported.

Lillehei et al. (1957) reported three successful cases, using cardiac bypass with potassium asystole, the last being in a considerable degree of cardiac failure; they mention in a footnote a further two cases of rupture found with other lesions. Their first case was explored through aortic and atrial incisions, the others through atrial incisions only. McGoon et al. (1958) described two cases, giving details in one only 
TABLE 1

REPORTED RESULTS IN THE REPAIR OF RUPTURED AORTIC SINUS ANEURYSM

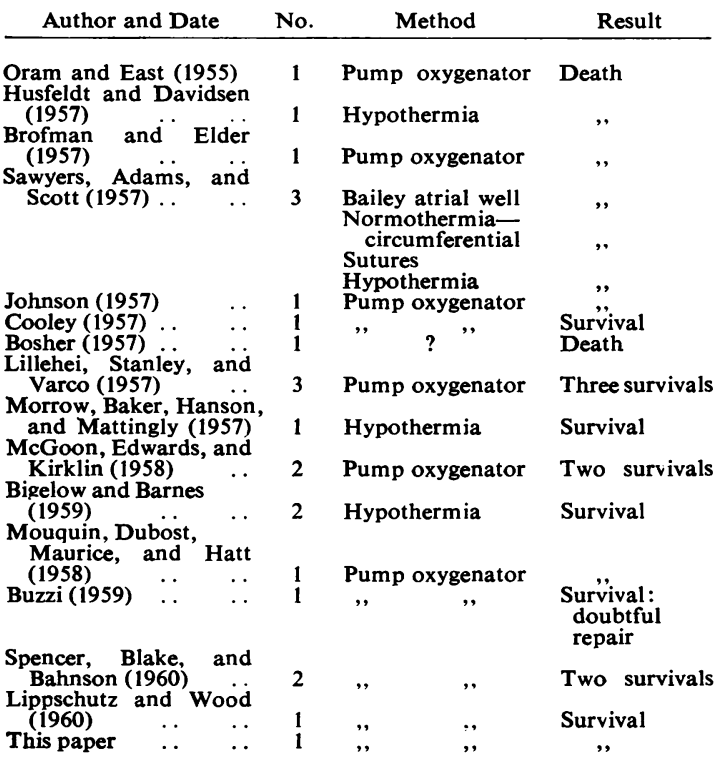

The authors reporting these cases did not necessarily perform the operations themselves. Confusion may have arisen as some of these cases have been reported in more than one paper; there may therefore be some omission or duplication in the above table.

performed on bypass with potassium arrest ; one had an associated ventricular septal defect repaired by a single Ivalon patch to cover both defects. Bigelow and Barnes (1959) described two cases, repaired with hypothermia alone in the first instance, and with bypass and potassium arrest in the second. The latter, although surviving with improvement of symptoms, continued to have a blood pressure of $120 / 40$. This patient had had bacterial endocarditis three years before operation and may presumably have another lesion, not repaired. Morrow et al. (1957) used an ingenious method, applied in one case with hypothermia. Before caval occlusion, a probe was passed through the aortic wall and the aneurysm into the right atrium and through the atrial wall. This was used to pass a thread through the defect, to which was tied a suitablesized plug of Ivalon, with a stem and a flange. After aortic and atrial incisions, this was led down the aorta, placed into the defect with the flange on the aortic side, and the stem of the plug was sutured into the aneurysm wall. The incisions were closed with lateral clamps and the operation successfully completed with only four minutes of caval occlusion.
Mouquin et al. (1958) report a successful repair; Lippschutz and Wood (1960) report one done by McGoon which may be the second reported in McGoon et al. (1958). Buzzi (1959) tells of a patient in whom survival was obtained but the physical signs and electrocardiographic changes were not modified ; dyspnoea and cardiac enlargement were diminished. Spencer et al. (1960) reported two successful repairs; the second, previously noted, is the only treated instance of a ruptured aneurysm arising from the left coronary sinus. It had burrowed into the atrial septum, and ruptured into the right atrium. The origin of the aneurysm was not immediately obvious, and the aorta was opened to discover it. Table I summarizes the surgical experience to date.

It is emphasized that this is a rapidly fatal condition which may be easily recognized clinically, and which is eminently treatable. As can be seen from Table $I$, the result of surgical treatment is now good, and, when successful, is extremely gratifying to all concerned.

\section{SUMMARY}

A successful repair of a ruptured aortic sinus aneurysm using total cardiac bypass is reported.

The possible variations which may be encountered in exploration of the heart in this condition are considered, and a review of previous surgical experience is made.

We are grateful to Professor A. M. Boyd for permission to report this case, and to Dr. E. G. Wade for criticism of the manuscript.

\section{REFERENCES}

Bigelow, W. G., and Barnes, W. T. (1959). Ann. Surg., 150, 117. Bosher, I. H., in discussion (1957). Surgery, 41, 41.

Brofman, B. L., and Elder, J. C. (1957). Circulation, 16, 77.

Buzzi, A. (1959). Amer. J. Cardiol., 4, 551.

Cooley, D. A., in discussion (1957). Surgery, 41, 41.

Edwards. J. E., and Burchell, H. B. (1956). Proc. Mayo Clin., 31, 407.

Gibbs, N. M., and Harris, E. L. (1961). Brit. Heart J., 23, 131.

Hall, B., and Pickard, S. D. (1959). Amer. J. Cardiol., 3, 404

Husfeldt, E., and Davidsen, H. G. (1957). Acta chir. scand. 111, 280

Jick, H., Karsarjian, P. J., and Barsky, M. (1959). Circulation, 19, 745 .

Johnson, J., in discussion (1957). Surgery, 41, 40.

Jones, A. M., and Langley, F. A. (1949). Brit. Heart J. . 11, 325.

Kieffer, S. A... and Winchell, P. (1960). Dis. Chest. 38, 79.

Lillehei, C. W., Stanley, P., and Varco, R. L. (1957). Ann. Surg. $146,459$.

Lippschutz. E. J., and Wood. L. W. (1960). Amer. J. Med., 28, 859.

McGoon, D. C. Edwards, J. E., and Kirklin, J. W. (1958). Ann. Surg., 147, 387

Morrow, A. G., Baker, R. R., Hanson, H. E., and Mattingly, T. W. (1957). Circulation, 16, 533.

Mouquin, M.. Dubost, C., Maurice, P., and Hatt, P. Y. (1958). Arch. Mal. Caur. 51, 935.

Oram, S., and East, T. (1955). Brit. Heart J., 17, 541.

Raman, T. K., and Menon, T. B. (1949). Indian Heart J., 1, 1.

Sawyers, J. L., Adams, J. E., and Scott, H. W. (1957). Surgery, 41, 26.

Semler, H. J., and Brandenburg, R. O. (1958). Proc. Mayo Clin., 33, 604.

Spencer, F. C., Blake, H. A., and Bahnson, H. T. (1960). Ann. Surg., $152,963$.

Steinberg, I., and Sammons, B. P. (1958). Ann. intern. Med., 49, 922

Warthen, R. O. (1949). Amer. Heart J., 37, 975.

Weiss, L. (1957). Brit. Heart J., 19, 138 .

Winfield, M. E. (1959). Amer. J. Cardiol., 3, 688. 